Scientific Review - Engineering and Environmental Sciences (2017), 26 (3), 401-411

Sci. Rev. Eng. Env. Sci. (2017), 26 (3)

Przegląd Naukowy - Inżynieria i Kształtowanie Środowiska (2017), 26 (3), 401-411

Prz. Nauk. Inż. Kszt. Środ. (2017), 26 (3)

http://iks.pn.sggw.pl

DOI 10.22630/PNIKS.2017.26.3.39

Sugiono SUGIONO, Oyong NOVAREZA, Ryan FARDIAN

Industrial Engineering Department, Brawijaya University, Malang Indonesia

\title{
Thermal comfort study of plastics manufacturing industry in converting process
}

Key words: thermal comfort, plastics manufacturing, CFD, PMV, PPD

\section{Introduction}

Physical environmental conditions are one of some factors that can give a major influence on human performances. Human body has adaptive physiological mechanism that allows us to tolerate a range of physical environmental conditions, but it is often at a cost to the body (Stanton, Hedge, Brookhuis, Salas $\&$ Hendrick, 2005). When physical environmental conditions give impact to human body, it also can affect human performance. It is necessary to adjust physical environmental conditions with the type of work performed by human. If physical environmental conditions match with the type of work performed, human performance will be stable or even increase. As one of physical environmental conditions, thermal can have significant impact to human performance. Thermal comfort can be defined as a condition of mind which expresses satisfaction with the thermal environment and is assessed by subjective evaluation (ASHRAE, 2004). Several factors that affect thermal conditions include humidity, air velocity, and air temperature. If the air temperature of the environment is too high, heat disorders like heat stroke, heat exhaustion, heat syncope, and heat rash may occur (OSHA, 2012).

This study is taking place on one of plastics manufacturing company that mainly produce blown plastic film in Indonesia. According to the research before, comfort thermal for Indonesian is around temperature $22.8-25.8^{\circ} \mathrm{C}$ with relative humidity 70\% (Yayi, 2012). Generally, people will get sweating at temperature $26^{\circ} \mathrm{C}$. Human endurance and human productivity starts decline at temperature $26-30^{\circ} \mathrm{C}$. Really hard situation will happen for people in temperature $33.5-35.5^{\circ} \mathrm{C}$. Environment temperature more than $36^{\circ} \mathrm{C}$ is not acceptable for people's productivity. 
There are three main processes in order to produce blown plastic film, namely extrusion, printing, and converting. In the extrusion process, plastic resin is melted and converted into plastic sheet that called blown plastic film. Furthermore, the blown plastic film will be given a pattern image on a printing process. In the final process, blown plastic film rolls will be cut to the desired shape and packaged. This study focused on converting process on a building that called $\mathrm{G}$ Building. Although $\mathrm{G}$ Building have 14 air ventilators inside that are arranged lengthwise, the air temperature inside that building is still quite high (more than $36^{\circ} \mathrm{C}$ ).

Results of early observations indicate that the effects due to heat exposure felt by worker in converting process decrease the performance of workers and increasing the mistakes made by workers. Based on the results of early observations, further research on thermal comfort experienced by workers in the converting process and prevention efforts are needed.

Heat is a form of energy that flows through in medium (solid, gas, fluid) from a point at one temperature to another point at a lower temperature. There are two forms of heat of concern in processing for comfort: sensible heat and latent heat (Koch-Neilsen, 2002). Sensible heat is the energy needed to increase a substance temperature with no change phase. On the other hand, latent heat is the amount of energy needed to change a substance phase, as example fluid to become steam. There are several methods that can be used to analyze the thermal comfort, some of which are predicted mean vote (PMV) model and predicted percentage of dissatisfied model (PPD). The PMV method is an index that represents the predicted mean vote (on the thermal sensation scale) of a large population exposed to a given environment, and is acknowledged as a standard international thermal environment indicator. The PMV index contents the combination and interdependencies of the following factors of thermal comfort: metabolic activity (met), clothing insulation (clo), air temperature, mean radiant temperature, air movement and humidity (ISO 7730, 1994).

The key six factors are combined together on the thermal sensation scale which called a predicted mean vote (PMV) index. The PMV index is derived from the physics of heat transfer combined with an empirical fit to human sensation and it establishes a thermal strain based on steady-state heat transfer between the body and the environment and assigns a comfort vote to that amount of heat stress. The table shows nine scales of PMV correlated to thermal perception and grade of physiological stress. The highest and lowest PMV index value will disturb worker's performance and their health condition. The disorder can include fatigue, cramps, loss of concentration and heat stroke (OSHS, 1997). Value of PMV under -3.5 is categorized as very cold in thermal perception with impact of extreme cold stress, PMV between -0.5 and 0.5 is categorized as comfortable perception with no thermal stress and PMV above 3.5 is categorized as very hot in thermal perception with the impact of extreme heat stress.

The PPD index is a derivative of the PMV index which it is used to determine the percentage of a person's discom- 
TABLE. Scales of PMV with thermal perception and grade off physical stress (Stanton et al., 2005)

\begin{tabular}{|c|c|c|c|}
\hline PMV & PET $\left[{ }^{\circ} \mathrm{C}\right]$ & Thermal perception & Grande of physiological stress \\
\hline$>-3.5$ & $>4$ & very cold & extreme cold stress \\
\hline-3.5 & 4 & cold & strong cold stress \\
\hline-2.5 & 8 & cool & moderate cold stress \\
\hline-1.5 & 13 & slightly cool & slight cold stress \\
\hline-0.5 & 18 & comfortable & no thermal stress \\
\hline 0.5 & 23 & slightly warm & slight heat stress \\
\hline 1.5 & 29 & warm & moderate heat stress \\
\hline 2.5 & 35 & hot & strong heat stress \\
\hline 3.5 & 41 & very hot & extreme heat stress \\
\hline$>3.5$ & $>41$ & \multicolumn{2}{|c}{}
\end{tabular}

fort against the thermal environment. Predicted percentage dissatisfied is the number of people (in percentage) who are not satisfied against the state of environment thermal. The greater percentage of PPD is the more residents who are dissatisfied. The maximum number of people dissatisfied with their comfort conditions is $100 \%$ and the recommended acceptable PPD range for thermal comfort from ASHRAE 55 is less than $15 \%$ of dissatisfied persons for an interior space (Stanton et al., 2005).

Computational fluid dynamics (CFD) simulation (Chung, 2002) is used to evaluate the existing thermal comfort of converting building based on PMV and PPD calculation. The CFD simulation can help to identify the flow of fluid inside the building to search the areas that need improvement. Moreover CFD was employed to do a simulation test for looking for the best modification of building model. Human comfort can be expressed in good condition with PMV index is targeted at $\cong 0$ and the value of PPD close to $5 \%$. When the thermal comfort of workers is achieved, labor productivity in the converting process will be increased automatically.

\section{Research method}

In order to determine the human thermal comfort (PMV index and PPD index) for workers in converting process, environment data and physiology data are collected. Converting process in this research is named the $G$ Building and has are 22 DB machines, 10 tables for plastic sheet recount, 5 punch machines, 5 press machines, 12 tables for packaging process, 5 SHF machines, 4 tables for finished good, 16 COSMO machines, and 14 air ventilators. The technical data of $\mathrm{G}$ Building can be described as:

- area door 1-36 $\mathrm{m}^{2}$, door 2-7.5 $\mathrm{m}^{2}$, door 3-24 $\mathrm{m}^{2}$, and door 4-12.5 $\mathrm{m}^{2}$;

- total area of glass $-63 \mathrm{~m}^{2}\left(2.25 \mathrm{~m}^{2}\right.$ $\times 28$;

- total number of workers - $22 \mathrm{em}$ ployees.

First step of the design action is creating all 3D CAD machinery and equipment model for G Building. Next step is assembling for all the CAD models into 
the same position and same condition with existing model. The assembly step is a final preparation process before simulation is started in improvement human thermal comfort. Figure 1 shows the final CAD model of G Building in the converting process of plastic manufacturing.
The next process is defining boundary conditions of $\mathrm{G}$ Building. The input value of air velocity is varies depend on the location of the door toward wind speed direction around the building. It will be defined on the boundary conditions include the air inlet path and the air

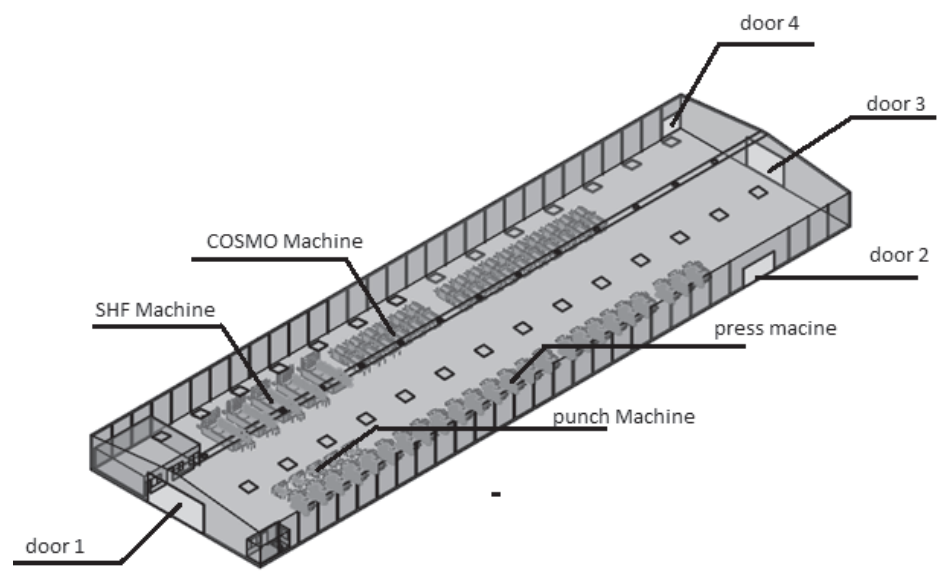

FIGURE 1. The 3D CAD model of G Building in the converting process of plastic manufacturing

In general, CFD simulation process consists of three main parts: the preprocessor, processor and post-processor. Preprocessor phase starts with the initial setting of the general settings. Analysis used is a type of internal analysis. Consideration of the Earth's gravity based on the Y-axis from 3D CAD models. Fluids or type of fluid being analyzed is the air with luminar and turbulent flow type. In this study, humidity levels are also taken into calculation. Wall conditions or the condition of the walls is assumed as adiabatic wall or walls that can not transfer heat and air from both sides. Initial conditions of environment condition is defined in existing condition with average air temperature $33^{\circ} \mathrm{C}$ and average relative humidity $80 \%$. outlet path in G Building. The boundary conditions at the entrance and exit of air in the G Building are defined as follows: 1. Inlet velocity $0.121 \mathrm{~m} \cdot \mathrm{s}^{-1}, 28^{\circ} \mathrm{C}$, with $70 \%$ relative humidity from front door.

2. Inlet velocity $0.007 \mathrm{~m} \cdot \mathrm{s}^{-1}, 34^{\circ} \mathrm{C}$, with $50 \%$ relative humidity from right door.

3. Inlet velocity $0.064 \mathrm{~m} \cdot \mathrm{s}^{-1}, 28^{\circ} \mathrm{C}$, with $70 \%$ relative humidity from left door.

4. Inlet velocity $0.013 \mathrm{~m} \cdot \mathrm{s}^{-1}, 33^{\circ} \mathrm{C}$, with $52 \%$ relative humidity from rear door.

5. Outlet volume flow $680,400 \mathrm{~cm}^{3} \cdot \mathrm{s}^{-1}$ from each air ventilator.

After defining boundary conditions, the next process is defining a heat source 
in $\mathrm{G}$ Building. There are five heat sources in G Building, that are:

1. Heat power of $1,800 \mathrm{~W}$ of each $\mathrm{DB}$ machine.

2. Heat power of 7,000 $\mathrm{W}$ of each press machine.

3. Heat power of $800 \mathrm{~W}$ of each SHF machine.

4. Heat power of 5,100 W of each COSMO machine.

5. Heat power of $491,348.7 \mathrm{~W}$ of sunlight through each glass on $\mathrm{G}$ Building roof.

\section{Result and discussion}

\section{Thermal comfort calculation of existing conditions}

Interpretation of CFD simulation in this study is described by a plot or cut pieces of a flat surface. Cut plot that used a cut plot with a height of $1.5 \mathrm{~m}$ from the Y-axis or as high as the human respiratory area. Figure 2 a shows the distribution of air temperature at a height of $1.5 \mathrm{~m}$ in $\mathrm{G}$ Building. The distribution of air temperature shown is in the range of dark blue for air temperature $28^{\circ} \mathrm{C}$ until the red color to the air temperature $34^{\circ} \mathrm{C}$.

From Figure 2 the distribution of air temperature in the area below the glass ceiling is at $\mathrm{G}$ Building has a high enough air temperature distribution. The location of workers with the lowest air temperature is $16^{\text {th }}$ worker's location with an air temperature of $29.46^{\circ} \mathrm{C}$. While the worker's location with the highest air temperature is $13^{\text {th }}$ worker's location with an air temperature of $33.86^{\circ} \mathrm{C}$. Figure $2 \mathrm{~b}$ shows the distribution of relative humidity at a height of $1.5 \mathrm{~m}$ in G Building. The distribution of relative humidity are shown in dark blue color range for relative humidity of $0 \%$ to red to $80 \%$ relative humidity. From the figure, it can be seen that the location of the worker with the lowest relative humidity is $13^{\text {th }}$ worker's locations with relative humidity of $35.16 \%$. While the location of the worker's with the highest relative humidity is $16^{\text {th }}$ worker's locations with relative humidity of $45.11 \%$.

Figure 2c shows the distribution of air velocity at a height of $1.5 \mathrm{~m}$ in $\mathrm{G}$ Building. The distribution of air velocity is displayed in the range of dark blue air velocity of $0 \mathrm{~m} \cdot \mathrm{s}^{-1}$ up to a red color to the air velocity of $1 \mathrm{~m} \cdot \mathrm{s}^{-1}$. From the figure, it can be seen that the location of the worker's location with the lowest air velocity is the location of $8^{\text {th }}$ worker's location with a air velocity of $0.146 \mathrm{~m} \cdot \mathrm{s}^{-1}$. While the location of the worker with the highest air velocity is the location of $18^{\text {th }}$ worker with air velocity of $0.539 \mathrm{~m} \cdot \mathrm{s}^{-1}$.

Thermal comfort of workers in converting process is defined using predicted mean vote index (PMV). First step of the assessment of PMV index is to assess the clothing insulation and metabolic rate workers based on reference (Stanton et al., 2005). Clothing insulation of workers is based on any item of clothing used by workers and metabolic rate of workers based on activities performed by workers. Result of observations show that worker's clothing insulation value is 0.42 clo. Workers metabolic rate value are 2.1 met for workers performing packing activities and 2.4 met for workers that operating machine. After assessing the clothing insulation and metabolic rate workers, the next step is to enter the value of clothing insulation, metabolic 

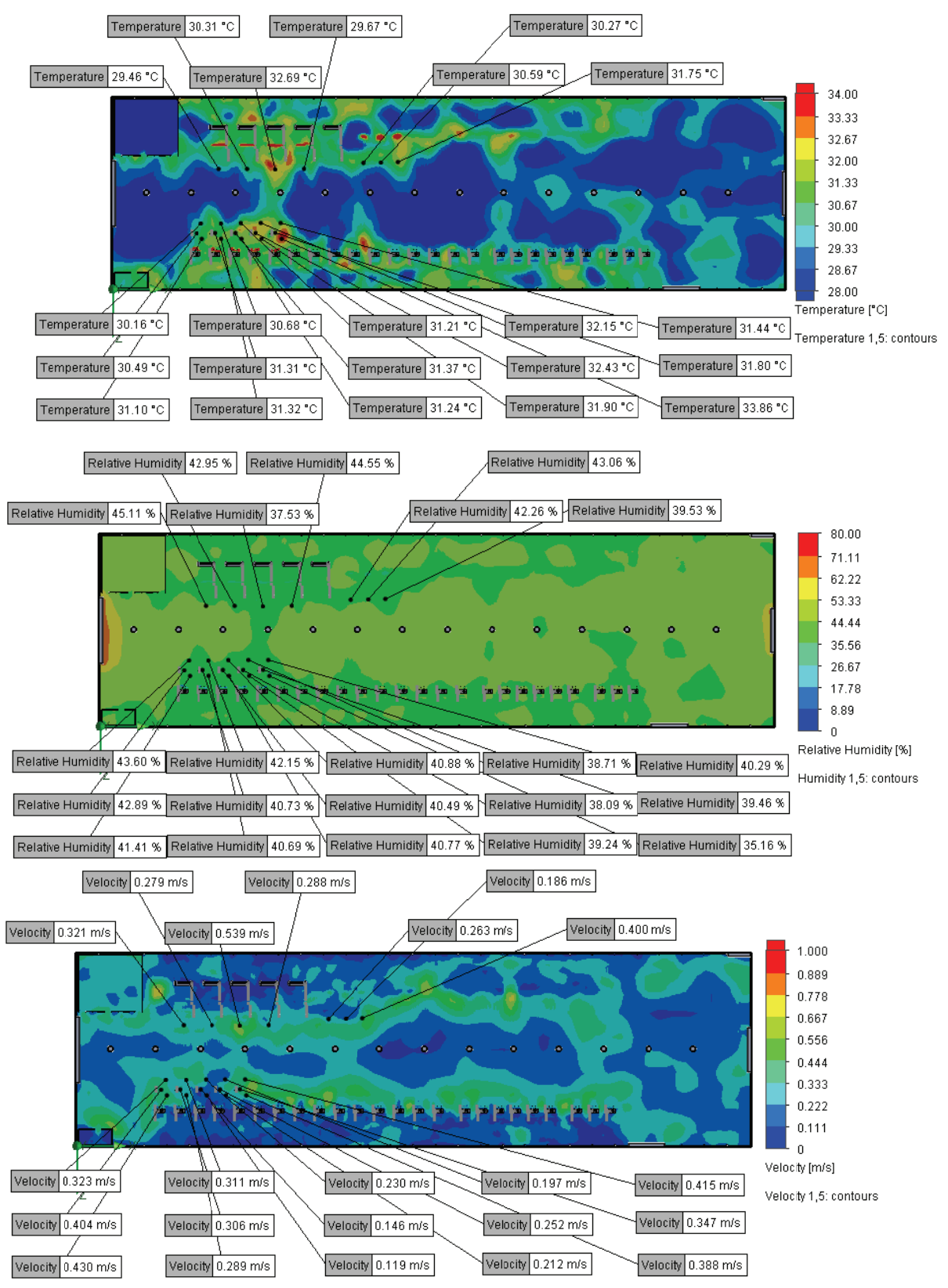

FIGURE 2. (a) Air temperature, (b) relative humidity, and (c) air velocity distribution of existing conditions 

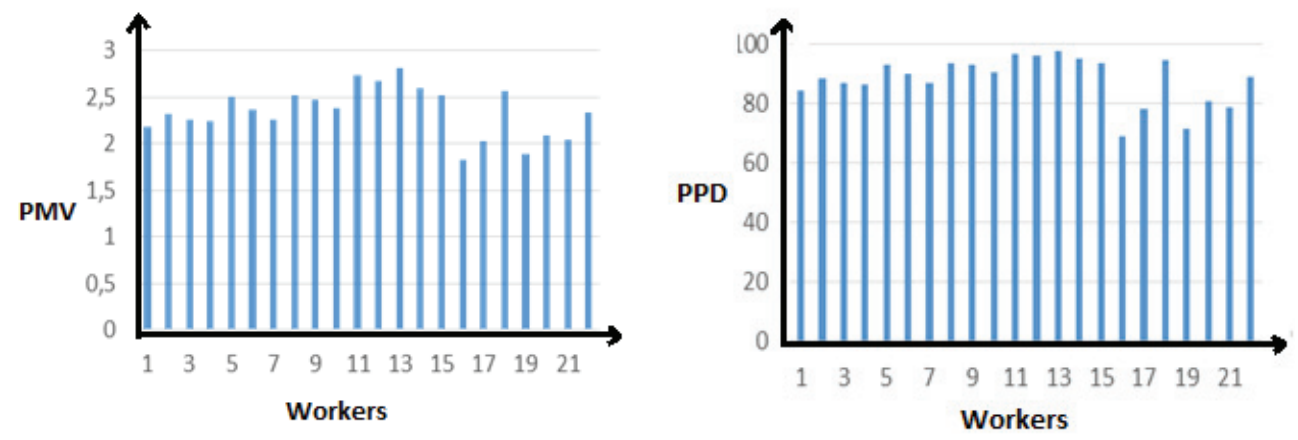

FIGURE 3. (a) Value of PMV, (b) value of PPD of existing conditions for 21 locations of workers in G Building

rate, and environmental data obtained from CFD simulation results into the equation PMV and PPD.

Figure $3 \mathrm{a}$ shows that the highest PMV value is perceived by $13^{\text {th }}$ worker that has value of 2.82. When viewed as a whole, based on Figure 3 the PMV value is at range from 1.83 to 2.82 . This means that thermal sensations experienced by workers is vary from slightly warm to warm. Figure $3 \mathrm{~b}$ shows that PPD value is range between 68.9 and $98 \%$. This means that less than $2 \%$ of workers in G Building will be thermally satisfied. It is far away from ASHRAE recommendation to provide thermal comfort in PPD 20\% (ASHRAE, 2004). As consequence, the factory management needs to modify the $\mathrm{G}$ Building or modify the workstation.

\section{Thermal comfort calculation of modification conditions}

The main factors of contributing PMV index for workers at converting process is the high value of air temperature. High air temperature value produced by glass ceiling in $\mathrm{G}$ Building and also from heat machine during manufacturing plastic. The CFD simulation is employed to configure the environment factors of air temperature, wind velocity and relative humidity. The simulation results are used as basic reference to do modification condition. According to Figure 2, it can be explained that heat configuration is dominated at near glass ceiling comparing to heat sources from machine or from manufacturing process.

Figure $4 \mathrm{a}$ shows the distribution of air temperature at a height of $1.5 \mathrm{~m}$ in $\mathrm{G}$ Building after improvement recommendation are implemented. The location of workers with the lowest air temperature is $18^{\text {th }}$ worker's location with an air temperature of $27.81^{\circ} \mathrm{C}$. While the worker's location with the highest air temperature is the location of $19^{\text {th }}$ worker with a air temperature of $29.93^{\circ} \mathrm{C}$. The highest air temperature values on the simulation results show a decrease of about $4^{\circ} \mathrm{C}$ comparing to the highest air temperature values in existing models. Figure $4 b$ shows the distribution of relative humidity at a height of $1.5 \mathrm{~m}$ in $\mathrm{G}$ Building after improvement recommendation are given. From the figure, it can be seen that the location of the worker with the lowest relative humidity is $19^{\text {th }}$ worker's locations with relative humidity of $44.05 \%$. While the location 


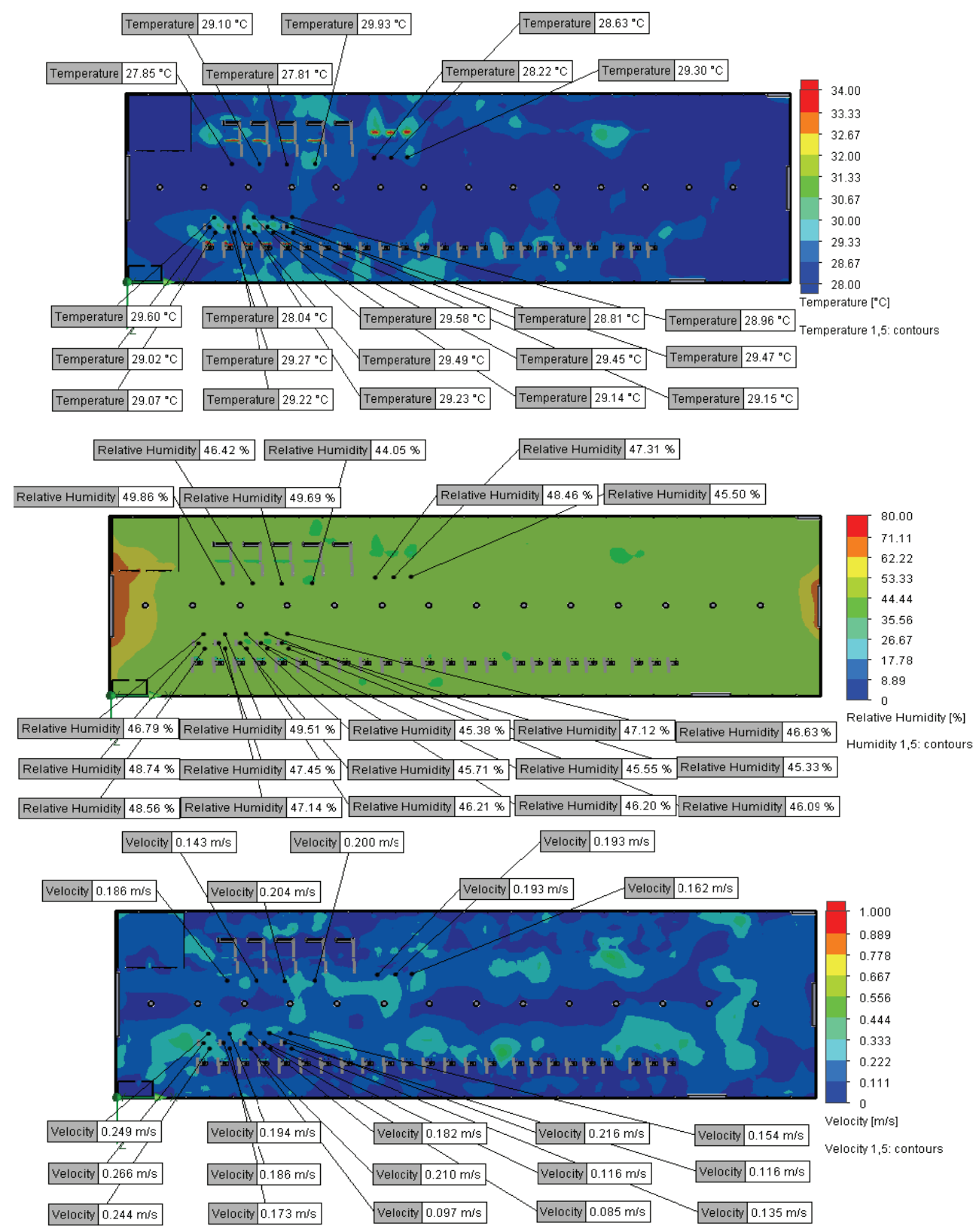

FIGURE 4. (a) Air temperature, (b) relative humidity, and (c) air velocity distribution of design recommendation 
of the worker with the highest relative humidity is $16^{\text {th }}$ worker's locations with relative humidity of $49.86 \%$. Figure $4 \mathrm{c}$ shows the distribution of air velocity at a height of $1.5 \mathrm{~m}$ in G Building after improvement recommendation are given. From the figure, it can be seen that the location of the worker with the lowest air velocity is the location of $7^{\text {th }}$ worker with a air velocity of $0.097 \mathrm{~m} \cdot \mathrm{s}^{-1}$. While the location of the worker with the highest air velocity is the location of $2^{\text {nd }}$ worker with air velocity of $0.266 \mathrm{~m} \cdot \mathrm{s}^{-1}$.

Figure 5a shows that the highest PMV value perceived by $9^{\text {th }}$ worker that has value of 2.18. When viewed as a whole, based on Figure 5a the PMV value is range between 1.63 and 2.18. This means that the highest PMV values on the simulation results show a decrease of about 0.64 point than the highest PMV values in existing models. Figure $5 \mathrm{~b}$ shows that PPD value is range between 58.2 and $84.2 \%$. This means that less than $15 \%$ of workers in G Building will be thermally satisfied and it shows $13.8 \%$ increasement from existing mod- els. In sort, the modification of building material, especially replace glass ceiling to reflective clear glass $6 \mathrm{~mm}$ with transmittance 23\% (Chaiyapinunt, Phueakphongsuriya, Mongkornsaksit \& Khomporn, 2004) was successfully reduce PPD level.

According to the simulation test, it gives some recommendation to reduce the heat stress in indoor factory workers, there are:

- looking for the best building direction to wind direction and sunrays intensity;

- plant more trees surrounding the factory building to reduce direct sunrays;

- provide more air circulation inside the building;

- selecting the best materials for building with reducing sunrays intensity e.g. ceiling, roof, floor, wall and door;

- installing fan, exhaust or air conditioning (AC) for reducing heat stress inside the building.

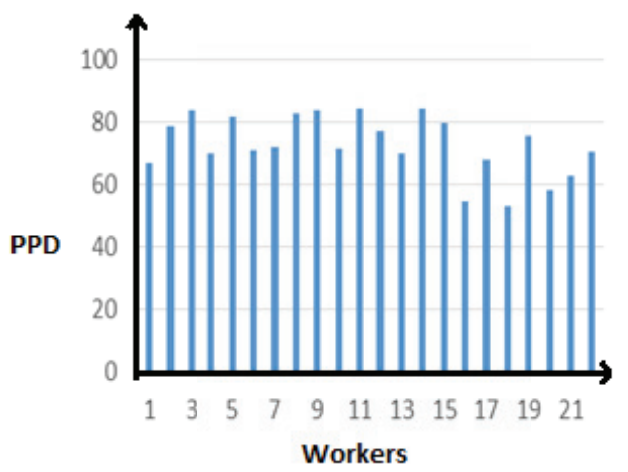

FIGURE 5. (a) Value of PMV, (b) value of PPD of modification conditions for 21 locations of workers in G Building 


\section{Conclusion}

Human thermal comfort of workers is successfully defined based on the predicted mean vote (PMV) scale and predicted percentage of dissatisfied (PPD) for converting process of plastic manufacturing. The existing measurement indicated that the highest PMV scale is 2.82 (hot condition) for $13^{\text {th }}$ worker's position. And the lowest PMV scale for existing model is 1.83 (warm condition) for $16^{\text {th }}$ worker's position. In average, the PMV for existing model equals 2.49 (warm to hot condition). Proportionally, the existing condition has PPD range between 68.9 and $98 \%$. It shows that $\cong 85 \%$ of occupants complain the thermal comfort in G Building of converting process of plastic manufacturing.

The research proposed to improve the human thermal comfort by reducing heat sources from clear glass ceiling. The ceiling glass replaced by reflective clear glass ceiling and it was implemented in CAD model also in CFD simulation. According to the simulation, the new average PMV equals 1.78 (warm condition) and PPD range between 58.2 and $84.2 \%$. Overall the $60 \%$ of workers will feel not comfort according to air quality condition correlated with thermal comfort. Further action should be done to increase thermal comfort at around $15 \%$ of PPD level by modified air circulation, planting more trees, modified water pool, looking for the best material building, air conditioning, etc.

\section{Acknowledgements}

Thanks to the Ministry of National Education of the Republic of Indonesia for supporting this paper. The authors are also grateful to the Work Design and Ergonomics Laboratory, Industrial Engineering Department, the Brawijaya University, Malang Indonesia for their extraordinary support.

\section{References}

ASHRAE (2004). ASHRAE Standard 55-2004, Thermal Environmental Conditions for $\mathrm{Hu}$ man Occupancy. Atlanta: ASHRAE.

Chaiyapinunt, S., Phueakphongsuriya, B., Mongkornsaksit, K. \& Khomporn, N. (2004). Performance Rating of Glass Windows and Glass Windows with Films in Aspect of Thermal Comfort and Heat Transmission. Elsevier B.V.

Chung, T.J. 2002. Computational Fluid Dynamics. Cambridge: Cambridge University Press.

Koch-Neilsen, H. (2002). Stay Cool: A Design Guide for the Built Environment in Hot Climates. Earthscan Publications.

OSHA (2012). Heat Stress. Minnesota: Department of Labor and Industry.

OSHS (1997). Extremes of Temperature. Wellington, New Zealan SDd.: The Occupational Safety and Health Sevice.

ISO (1994). ISO 7730: Moderate Thermal Environments - Determination of the PMV and PPD Indices and Specification of the Conditions for Thermal Comfort. Switzerland: ISO.

Stanton, N., Hedge, A., Brookhuis, K., Salas, E. \& Hendrick, H. (2005). Handbook of Human Factors and Ergonomics Methods. United State of America: CRC Press.

Yayi, A. (2012). Comfort Temperature or the Low-Income Group in a Hot-Humid Climate. Proceeding of $7^{\text {th }}$ Windsor Conference, London UK.

\section{Summary}

Thermal comfort study of plastics manufacturing industry in converting process. Thermal comfort is one of ergonomics factors that can create a significant impact to workers performance. For a better 
thermal comfort, several environment factors (air temperature, wind speed and relative humidity) should be considered in this research. The object of the study is a building for converting process of plastics manufacturing industry located in Malang, Indonesia. The maximum air temperature inside the building can reach as high as $36^{\circ} \mathrm{C}$. The result of this study shows that heat stress is dominantly caused by heat source from machine and wall building. The computational fluid dynamics (CFD) simulation is used to show the air characteristic through inside the building. By using the CFD simulation, some scenarios of solution are successfully presented. Employees thermal comfort was investigated based on predicted mean vote model (PMV) and predicted percentage of dissatisfied model (PPD). Existing condition gives PMV in range from 1.83 to 2.82 and PPD in range from 68.9 to $98 \%$. Meanwhile, modification of ventilation and replacing ceiling material from clear glass into reflective clear glass gave significant impact to reduce PMV into range from 1.63 to 2.18 and PPD into range from 58.2 to $84.2 \%$. In sort, new design converting building process has more comfortable for workers.

\section{Authors' address:}

Sugiono Sugiono, Oyong Novareza, Ryan

Fardian

Brawijaya University

Industrial Engineering Department

Malang 65145

Indonesia

e-mail: sugiono_ub@ub.ac.id 